\title{
MANAGEMENT OF ENDOCRINE DISEASE Hypothyroidism-associated hyponatremia: mechanisms, implications and treatment
}

\author{
G Liamis, T D Filippatos, A Liontos and M S Elisaf \\ Department of Internal Medicine, School of Medicine, University of Ioannina, Ioannina, Greece
}

\author{
Correspondence \\ should be addressed \\ to T D Filippatos \\ Email \\ filtheo@gmail.com
}

\begin{abstract}
Background: Patients with moderate to severe hypothyroidism and mainly patients with myxedema may exhibit reduced sodium levels (<135 mmol/L).

Summary: The aim of this short review is the presentation of the mechanisms of hyponatremia and of the available data regarding its implications and treatment in patients with hypothyroidism. Hypothyroidism is one of the causes of hyponatremia, thus thyroid-stimulating hormone determination is mandatory during the evaluation of patients with reduced serum sodium levels. The main mechanism for the development of hyponatremia in patients with chronic hypothyroidism is the decreased capacity of free water excretion due to elevated antidiuretic hormone levels, which are mainly attributed to the hypothyroidism-induced decrease in cardiac output. However, recent data suggest that the hypothyroidism-induced hyponatremia is rather rare and probably occurs only in severe hypothyroidism and myxedema. Other possible causes and superimposed factors of hyponatremia (e.g. drugs, infections, adrenal insufficiency) should be considered in patients with mild/moderate hypothyroidism. Treatment of hypothyroidism and fluid restriction are usually adequate for the management of mild hyponatremia in patients with hypothyroidism. Patients with possible hyponatremic encephalopathy should be urgently treated according to current guidelines.

Conclusions: Severe hypothyroidism may be the cause of hyponatremia. All hypothyroid patients with low serum sodium levels should be evaluated for other causes and superimposed factors of hyponatremia and treated accordingly.
\end{abstract}

\section{Introduction}

Decreased thyroid hormone levels are usually associated with underlying thyroid disease (primary hypothyroidism), but occasionally may be caused by disorders of the hypothalamic-pituitary axis resulting in reduced secretion of thyroid-stimulating hormone (TSH) or thyrotropin-releasing hormone (TRH) (secondary or tertiary hypothyroidism) $(1,2)$. Patients with moderate to severe hypothyroidism and mainly patients with myxedema may exhibit reduced sodium levels $(<135 \mathrm{mmol} / \mathrm{L})(3,4)$. Thus, hypothyroidism is one of
() 2017 European Society of Endocrinology Printed in Great Britain the causes of hyponatremia, and TSH determination is mandatory during the evaluation of patients with reduced serum sodium levels $(5,6,7)$. Furthermore, the exclusion of hypothyroidism is one of the prerequisites for the diagnosis of the syndrome of inappropriate antidiuretic hormone $(\mathrm{ADH})$ secretion $(\mathrm{SIADH})(6,7,8)$.

The aim of this short review is the presentation of the mechanisms of hyponatremia and the available data regarding its implications and treatment in patients with hypothyroidism. 


\section{Possible mechanisms of hyponatremia in patients with hypothyroidism}

Acute hypothyroidism is usually seen in patients with differentiated thyroid cancer (papillary and follicular) who undergo preparation for radioiodine therapy, during which thyroid hormone treatment is withheld. In this setting of acute hypothyroidism, decreased glomerular filtration rate (GFR) that can directly decrease free water excretion by diminishing water delivery to the diluting segments is the most important mechanism of hyponatremia $(9,10)$. In the setting of radioiodine treatment, patients are instructed to follow low-iodine diet and receive increased fluid intake. Additionally, radioiodine administration is associated with nausea and anxiety (which are very potent stimuli of antidiuretic hormone secretion) and these factors combined may contribute to hypothyroidismassociated hyponatremia (10).

The main mechanism for the development of hyponatremia in patients with chronic hypothyroidism is the decreased capacity of free water excretion due to elevated ADH levels (Fig. 1). The increase in ADH levels has been mainly attributed to the hypothyroidism-induced decrease in cardiac output, which stimulates the carotid sinus baroreceptors and induces the release of $\mathrm{ADH}$ $(11,12,13,14)$. Thus, hyponatremia in most of hypothyroid patients is the result of the inability to suppress maximally the secretion of $\mathrm{ADH}$, which results in reduced water excretion $(3,15)$. Indeed, it has been shown that the impaired water excretion in hypothyroidism is mediated through the upregulation of ADH-induced acquaporin-2 expression in the collecting tubules (15).

However, reduced cardiac output is not the sole possible mechanism of hyponatremia in at least some patients with chronic hypothyroidism (Fig. 1). Another contributing factor to increased ADH levels in patients with myxedema is the accumulation of interstitial mucopolyccharides that results in fluid retention and decreased effective arterial blood volume leading to $\mathrm{ADH}$-mediated water retention and reduced sodium levels $(16,17)$. Additionally, some hypothyroid patients exhibit increased urine sodium concentration that points to the diagnosis of SIADH and not to reduced cardiac output (18). Impaired renal function seems to play a role in the development of hyponatremia in patients with hypothyroidism. In these patients, the impairment

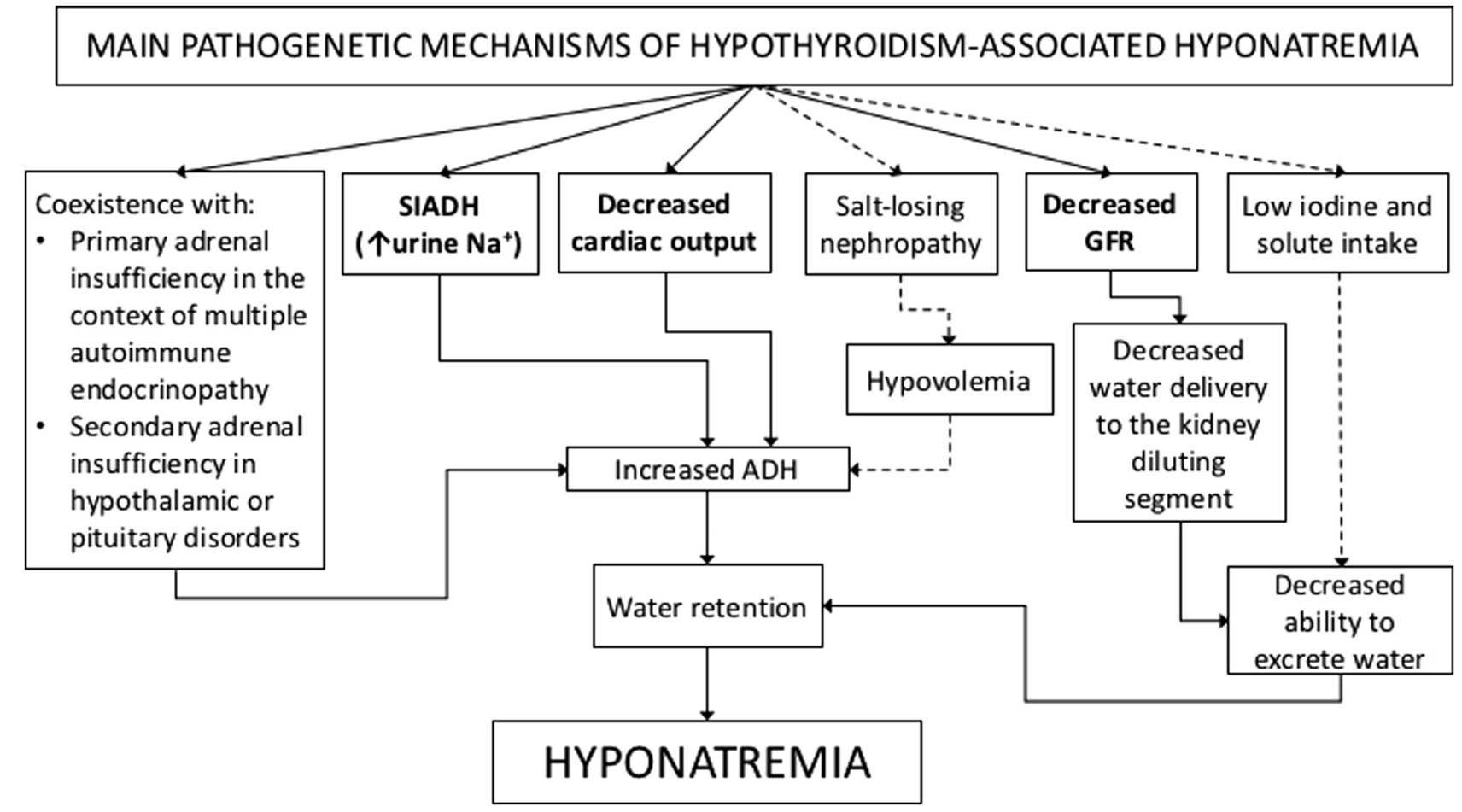

Figure 1

Implicating mechanisms of hyponatremia in patients with chronic hypothyroidism. The most important mechanisms are shown with bold letters and the rare mechanisms are shown with dashed lines. ADH, antidiuretic hormone; GFR, glomerular filtration rate; SIADH, syndrome of inappropriate antidiuretic hormone secretion. 
in kidney function (reduced GFR) results in decreased water delivery to the diluting segments of the kidney and subsequently reduced capacity for water excretion ( 9 , 19, 20). Moreover, a low-iodine diet is usually associated with low solute intake that may contribute to the development of hyponatremia (21). Generally, low-iodine diet is associated with the occurrence of hyponatremia especially in elderly patients ( $>65$ years), in females, as well as in diuretic (thiazides)-treated individuals (22). Finally, a case report proposed salt-losing nephropathy as a possible mechanism of mild hyponatremia (serum sodium $134 \mathrm{mmol} / \mathrm{L}$ ) in a hypothyroid patient with hypovolemia and multiple electrolyte abnormalities. It was proposed that thyroid hormone is essential for the expression of active transport pumps in the renal tubules, especially the $\mathrm{Na}^{+}-\mathrm{K}^{+}$-ATPase pumps, and hypothyroidism may be infrequently related with multiple electrolyte abnormalities associated with volume losses (23). Figure 1 describes the main pathogenetic mechanisms of chronic hypothyroidism-associated hyponatremia. In certain patients, more than one of these mechanisms may coexist.

\section{How real is the association between hyponatremia and hypothyroidism?}

Generally, the association between hypothyroidism and hyponatremia is rather week. A retrospective study showed that acute hypothyroidism in the setting of thyroid hormone therapy withdrawal in patients with differentiated thyroid cancer was associated with mild hyponatremia in only $3.9 \%$ of 128 patients, whereas none of the patients developed severe hyponatremia (20). Similarly, in a prospective analysis of 212 consecutive thyroid cancer patients, a small difference was observed between pre- and post-isolation sodium levels (mean \pm S.D. preisolation: $139.5 \pm 2.3$, postisolation: $137.8 \pm 3.0 \mathrm{mEq} / \mathrm{L}$ ) (10). Additionally, mild hyponatremia $(\geq 130 \mathrm{mEq} / \mathrm{L})$ was observed only in 18 patients $(8.5 \%)$ and moderate hyponatremia $(\geq 120 \mathrm{mEq} / \mathrm{L})$ only in $4(1.9 \%)$ patients. This prospective study also showed that in this setting, serum sodium concentration may not need to be monitored, unless patients have 'risk factors' for developing hyponatremia such as impaired renal function or are receiving diuretics. Additionally, increased age and female gender are associated with lower serum sodium concentration in the setting of acute hypothyroidism (10). Regarding chronic hypothyroidism, a retrospective analysis of data from 9012 patients admitted to an Emergency Medicine Department reported an increased prevalence of hyponatremia in patients having high TSH levels compared with patients having normal TSH levels ( $14 \%$ vs $9 \%, P<0.01)(24)$. However, the difference in serum sodium concentration between these groups, although statistically significant, was rather nonclinically relevant (138 vs $139 \mathrm{mEq} / \mathrm{L}, P<0.01$ ). Additionally, serum sodium concentration did not correlate with serum TSH levels; however, the most active free triiodothyronine $\left(\mathrm{T}_{3}\right)$ correlated significantly with serum sodium levels. It should be mentioned that only patients with severe thyroid dysfunction exhibited clinically relevant electrolyte abnormalities, including decreased serum sodium levels (24).

Additionally, the incidence of hypothyroidism is low in patients with hyponatremia. In a series of patients with hyponatremia $\left(n=204, \mathrm{Na}^{+}<130 \mathrm{mEq} / \mathrm{L}\right)$, hypothyroidism was evident only in two cases (25). Other authors reported that hypothyroidism was not a major cause of low sodium levels even in cases of unexplained hyponatremia (26).

Other studies have questioned the direct correlation between hypothyroidism and hyponatremia. For example, a study including 33912 patients reported no significant difference in serum sodium levels between euthyroid and hypothyroid patients (27). Additionally, no significant difference was shown in the proportion of euthyroid and hypothyroid patients with serum sodium concentration $<135 \mathrm{mEq} / \mathrm{L}$ (11.4\% vs 12.8\%) (27). Another retrospective analysis from the Emergency Department or the Medical Intensive Care Unit of a University Hospital also showed no clinically significant alterations in serum sodium concentration in hypothyroid patients (mean serum sodium levels in hypothyroid group was $137.8 \mathrm{mEq} / \mathrm{L}$ and in euthyroid group was $137.4 \mathrm{mEq} / \mathrm{L}$ ) (28). Additionally, the prevalence of hyponatremia was also similar in hypothyroid and euthyroid individuals ( $19.7 \%$ vs $20.7 \%$, $P=$ NS) (28). Moreover, no clinically relevant association between newly diagnosed hypothyroidism and decreased sodium levels was shown in a retrospective analysis $(n=999)$, in which every increase in TSH by $10 \mathrm{mIU} / \mathrm{L}$ correlated with a decrease in serum sodium by only $0.14 \mathrm{mEq} / \mathrm{L}$ (4). Furthermore, studies in infants with congenital hypothyroidism did not show an association between hypothyroidism and hyponatremia (29). Thus, in the cases of congenital hypothyroidism and hyponatremia, other causes of decreased serum sodium concentration (e.g. malnutrition, volume depletion, tubulopathies, SIADH) should be searched (17).

It has been suggested that the association between hyponatremia and hypothyroidism may at least be mediated by other comorbidities, including hypovolemia, 
nausea, infections or drugs affecting water homeostasis, which may induce increased $\mathrm{ADH}$ secretion, water retention and hyponatremia $(17,30,31)$. Thus, other causes of decreased sodium levels (including drugs) should be carefully excluded in patients with mild/ moderate hypothyroidism and hyponatremia $(7,32)$. Indeed, it has been suggested that hypothyroidism should be included in the differential diagnosis of hyponatremia only in patients with severe hypothyroidism (TSH levels $>50 \mathrm{mIU} / \mathrm{L}$ ) or with symptoms or signs of myxedema (33). However, clinicians should have in mind that severe hypothyroidism can exist with TSH levels below $50 \mathrm{mIU} / \mathrm{L}$. Indeed, a significant negative correlation between age and TSH levels has been shown in thyroid cancer patients 4 weeks after the withdrawal of thyroxine therapy in preparation for radioiodine scan/treatment (34). Additionally, severe secondary hypothyroidism can be the cause of low thyroid hormones.

Patients with metastatic thyroid cancer may exhibit severe symptomatic hyponatremia if thyroxine treatment is stopped before the administration of radioactive iodine $(35,36,37)$. However, low-iodine diet associated with low solute intake, as well as the underlying neoplasia, may contribute to the development of hyponatremia in these cases (21). Thus, serum sodium monitoring is crucial in patients with high risk of hyponatremia who are in lowiodine diet (22).

Finally, hypothyroidism observed in patients with the polyglandular autoimmune syndrome type II is usually accompanied by adrenal insufficiency resulting in hyponatremia (38). Similarly, the simultaneous presence of glucocorticoid deficiency should be suspected in cases of secondary hypothyroidism $(5,39)$.

\section{Clinical implications}

The assessment of the extracellular volume status is of vital importance in the evaluation of hyponatremia (7). Hypothyroidism-induced hyponatremia is usually euvolemic; thus, the presence of hypovolemia may suggest coexistent primary adrenal insufficiency or less frequently salt-losing nephropathy (6).

As aforementioned data clearly suggests, hypothyroidism should not be considered the sole cause of the low serum sodium in hypothyroid patients with TSH levels $<50 \mathrm{mIU} / \mathrm{L}$ (33). In this setting, hypothyroidism should be considered as a possible superimposed factor and other causes of hyponatremia should be investigated. In euvolemic hypothyroid patients with TSH $<50 \mathrm{mIU} / \mathrm{mL}$, if no other obvious cause of hyponatremia can be identified after a thorough diagnostic work up and normonatremia has not been achieved after thyroid hormone replacement, the possibility of idiopathic SIADH, which is not infrequently observed especially in the elderly, should be suspected. In these cases, careful and repeated monitoring for the presence of an occult tumor (particularly pulmonary) is essential (7).

The attribution of hyponatremia to hypothyroidism is a diagnostic challenge for clinicians, even in cases of myxedematous coma, since myxedema crisis is often induced by an underlying infection, respiratory or central nervous system illness or drugs (e.g. sedatives or antidepressants), which are all well-established causes of hyponatremia $(32,40)$. It is also possible that myxedema and hyponatremia may have a common underlying cause (e.g. amiodarone) (32). Hypothyroidism also frequently coexists with diabetes mellitus, which is associated with hyponatremia through several underlying mechanisms $(41,42)$. Additionally, in hyperglycemic states, it is imperative to correct the serum sodium concentration for the degree of hyperglycemia (43). Another important step in the approach of any patient with hyponatremia is to exclude the possibility that the decreased serum sodium levels are due to an artifact. Potential causes of pseudohyponatremia in patients with hypothyroidism are dyslipidemia (especially if diabetes mellitus coexists) and hypergammaglobulinemia (in hypothyroidism of autoimmune origin) (44). Consequently, hyponatremia of multifactorial origin may be seen in patients with hypothyroidism and the presence of common causes or superimposed factors should be meticulously investigated.

\section{Treatment of hyponatremia in hypothyroidic patients}

In most cases, hyponatremia associated with hypothyroidism is usually mild; thus, thyroid hormone replacement and moderate fluid restriction are generally enough to correct serum sodium levels. More severe hyponatremia is mainly observed in patients who have severe hypothyroidism usually accompanied by altered mental status. It should be emphasized that the neurological picture of myxedema and hyponatremic encephalopathy is often extremely difficult to be distinguished. In this case, urgent treatment of hyponatremia may be indicated to determine whether the low serum sodium levels contribute to the patient's neurological symptoms (45). It has been proposed that treatment of hyponatremia should be attempted with water restriction and normal saline only in patients with serum sodium concentration $<120 \mathrm{mEq} / \mathrm{L}$, 
while in patients with higher serum sodium levels, water restriction is usually adequate. More aggressive treatment (hypertonic saline solution plus furosemide) should be used cautiously to avoid inadvertent correction of hyponatremia with its devastating consequences (osmotic demyelination syndrome) (46).

However, taking into account the rarity of hypothyroidism-related hyponatremia and the lack of relative studies, we believe that therapy of this entity should not be deviated from the principles of treating hyponatremia of any cause $(45,47,48)$. Specifically, normal saline should not be administered in patients with suspicious hyponatremic encephalopathy because no significant change or even a decrease in serum sodium levels can be observed $(49,50)$. On the contrary, in cases with severe symptomatic hyponatremia, $100 \mathrm{~mL}$ of $3 \%$ $\mathrm{NaCl}(2 \mathrm{~mL} / \mathrm{kg}$ body weight) should be immediately administered. If necessary up to two additional infusions at 10-min intervals may be given (45). Normal saline should be restricted only in rare cases of hypothyroidisminduced hypovolemic hyponatremia $(50,51)$.

\section{Conclusions}

The hypothyroidism-induced hyponatremia is rather rare and probably occurs only in severe hypothyroidism. Even in myxedema coma, however, other possible causes and superimposed factors of hyponatremia (e.g. drugs, infections, adrenal insufficiency) should be considered.

\section{Declaration of interest}

This review was written independently; no company or institution supported it financially. Professor M Elisaf has received speaker honoraria, consulting fees and research funding from AstraZeneca, Schering Plough, Merck, Pfizer, Solvay, Abbott, Boehringer Ingelheim and Fournier, and has participated in clinical trials with AstraZeneca, Merck, Sanofi-Synthelabo, Solvay, Glaxo, Novartis, Pfizer and Fournier. The authors have given talks and attended conferences sponsored by various pharmaceutical companies, including Bristol-Myers Squibb, Pfizer, Lilly, Abbott, Amgen, AstraZeneca, Novartis, Vianex, Teva and MSD.

\section{Funding}

This research did not receive any specific grant from any funding agency in the public, commercial or not-for-profit sector.

\section{References}

1 Devdhar M, Ousman YH \& Burman KD. Hypothyroidism. Endocrinology and Metabolism Clinics of North America 200736 595-615. (doi:10.1016/j.ecl.2007.04.008)

2 Garber JR, Cobin RH, Gharib H, Hennessey JV, Klein I, Mechanick JI, Pessah-Pollack R, Singer PA, Woeber KA \& Abbott RD. Clinical practice guidelines for hypothyroidism in adults: cosponsored by the American Association of Clinical Endocrinologists and the American Thyroid Association. Endocrine Practice 201218 988-1028. (doi:10.4158/EP12280.GL)

3 Skowsky WR \& Kikuchi TA. The role of vasopressin in the impaired water excretion of myxedema. American Journal of Medicine 197864 613-621. (doi:10.1016/0002-9343(78)90581-8)

4 Warner MH, Holding S \& Kilpatrick ES. The effect of newly diagnosed hypothyroidism on serum sodium concentrations: a retrospective study. Clinical Endocrinology 200664 598-599. (doi:10.1111/j.13652265.2006.02489.x)

5 Liamis G, Milionis HJ \& Elisaf M. Endocrine disorders: causes of hyponatremia not to neglect. Annals of Medicine 201143 179-187. (doi:10.3109/07853890.2010.530680)

6 Milionis HJ, Liamis GL \& Elisaf MS. The hyponatremic patient: a systematic approach to laboratory diagnosis. Canadian Medical Association Journal 2002166 1056-1062.

7 Filippatos TD, Liamis G, Christopoulou F \& Elisaf MS. Ten common pitfalls in the evaluation of patients with hyponatremia. European Journal of Internal Medicine 201629 22-25. (doi:10.1016/j.ejim.2015.11.022)

8 Adrogue HJ \& Madias NE. Hyponatremia. New England Journal of Medicine 2000342 1581-1589. (doi:10.1056/NEJM200005253422107)

9 Schmitz PH, de Meijer PH \& Meinders AE. Hyponatremia due to hypothyroidism: a pure renal mechanism. Netherlands Journal of Medicine 200158 143-149. (doi:10.1016/S0300-2977(01)00081-X)

10 Hammami MM, Almogbel F, Hammami S, Faifi J, Alqahtani A \& Hashem W. Acute severe hypothyroidism is not associated with hyponatremia even with increased water intake: a prospective study in thyroid cancer patients. BMC Endocrine Disorders 20131327. (doi:10.1186/1472-6823-13-27)

11 Derubertis FR Jr, Michelis MF, Bloom ME, Mintz DH, Field JB \& Davis BB. Impaired water excretion in myxedema. American Journal of Medicine 197151 41-53. (doi:10.1016/0002-9343(71)90322-6)

12 Hanna FW \& Scanlon MF. Hyponatraemia, hypothyroidism, and role of arginine-vasopressin. Lancet 1997350 755-756. (doi:10.1016/ S0140-6736(05)62563-9)

13 Kreisman SH \& Hennessey JV. Consistent reversible elevations of serum creatinine levels in severe hypothyroidism. Archives of Internal Medicine 1999159 79-82. (doi:10.1001/archinte.159.1.79)

14 Filippatos TD \& Elisaf MS. Hyponatremia in patients with heart failure. World Journal of Cardiology 20135 317-328. (doi:10.4330/wjc. v5.i9.317)

15 Chen YC, Cadnapaphornchai MA, Yang J, Summer SN, Falk S, Li C, Wang W \& Schrier RW. Nonosmotic release of vasopressin and renal aquaporins in impaired urinary dilution in hypothyroidism. American Journal of Physiology: Renal Physiology 2005289 F672-F678. (doi:10.1152/ajprenal.00384.2004)

16 Hierholzer K \& Finke R. Myxedema. Kidney International Supplements 199759 S82-S89.

17 Abuzaid AS \& Birch N. The controversies of hyponatraemia in hypothyroidism: weighing the evidence. Sultan Qaboos University Medical Journal 201515 e207-e212.

18 Archambeaud-Mouveroux F, Dejax C, Jadaud JM, Vincent D, Laroumagne G, Hessel L \& Laubie B. [Myxedema coma with hypervasopressinism. 2 cases]. Annales de Médecine Interne 1987138 114-118.

19 Iwasaki Y, Oiso Y, Yamauchi K, Takatsuki K, Kondo K, Hasegawa H \& Tomita A. Osmoregulation of plasma vasopressin in myxedema. Journal of Clinical Endocrinology and Metabolism 199070 534-539. (doi:10.1210/jcem-70-2-534)

20 Baajafer FS, Hammami MM \& Mohamed GE. Prevalence and severity of hyponatremia and hypercreatininemia in shortterm uncomplicated hypothyroidism. Journal of Endocrinological Investigation 199922 35-39. (doi:10.1007/BF03345476)

21 Pantalone KM \& Hatipoglu BA. Hyponatremia and the thyroid: causality or association? Journal of Clinical Medicine 20144 32-36. (doi:10.3390/jcm4010032) 
22 Li JH, He ZH, Bansal V \& Hennessey JV. Low iodine diet in differentiated thyroid cancer: a review. Clinical Endocrinology 201684 3-12. (doi:10.1111/cen.12846)

23 Bautista AA, Duya JE \& Sandoval MA. Salt-losing nephropathy in hypothyroidism. BMJ Case Reports 20142014 bcr2014203895.

24 Schwarz C, Leichtle AB, Arampatzis S, Fiedler GM, Zimmermann H, Exadaktylos AK \& Lindner G. Thyroid function and serum electrolytes: does an association really exist? Swiss Medical Weekly 2012142 w13669. (doi:10.4414/smw.2012.13669)

25 Liamis G, Mitrogianni Z, Liberopoulos EN, Tsimihodimos V \& Elisaf M. Electrolyte disturbances in patients with hyponatremia. Internal Medicine 200746 685-690. (doi:10.2169/ internalmedicine.46.6223)

26 Katoch CD, Brar KS \& Singh B. Evaluation of thyroid and adrenal functions in patients with hyponatremia. Medical Journal Armed Forces India 201369 237-240. (doi:10.1016/j.mjafi.2013.01.003)

27 Croal BL, Blake AM, Johnston J, Glen AC \& O'Reilly DS. Absence of relation between hyponatraemia and hypothyroidism. Lancet 1997 350 1402. (doi:10.1016/s0140-6736(05)65181-1)

28 Berndt M, Harbeck B, Lindner U, Pauli D \& Haas CS. Hyponatremia due to thyrotropin deficiency: a fairy tale? Mayo Clinic Proceedings 201590 1305-1307. (doi:10.1016/j.mayocp.2015.05.019)

29 Asami T \& Uchiyama M. Sodium handling in congenitally hypothyroid neonates. Acta Paediatrica 200493 22-24. (doi:10.1111/j.1651-2227.2004.tb00668.x)

30 Liamis G, Filippatos TD \& Elisaf MS. Electrolyte disorders associated with the use of anticancer drugs. European Journal of Pharmacology 2016777 78-87. (doi:10.1016/j.ejphar.2016.02.064)

31 Liamis G, Filippatos TD \& Elisaf MS. Thiazide-associated hyponatremia in the elderly: what the clinician needs to know. Journal of Geriatric Cardiology 201613 175-182. (doi:10.11909/j. issn.1671-5411.2016.02.001)

32 Liamis G, Milionis H \& Elisaf M. A review of drug-induced hyponatremia. American Journal of Kidney Diseases 200852 144-153. (doi:10.1053/j.ajkd.2008.03.004)

33 Aylwin S, Burst V, Peri A, Runkle I \& Thatcher N. 'Dos and don'ts' in the management of hyponatremia. Current Medical Research and Opinion 201531 1755-1761. (doi:10.1185/03007995.2015.1072706)

34 Hammami MM, Al-Saihati B \& Al-Ahmari S. Influence of age and sex in modulating TSH level in primary hypothyroidism. Annals of Saudi Medicine 199515 575-578.

35 Shakir MK, Krook LS, Schraml FV, Hays JH \& Clyde PW. Symptomatic hyponatremia in association with a low-iodine diet and levothyroxine withdrawal prior to I131 in patients with metastatic thyroid carcinoma. Thyroid 200818 787-792. (doi:10.1089/thy.2008.0050)

36 Nozu T, Yoshida Y, Ohira M \& Okumura T. Severe hyponatremia in association with $\mathrm{I}(131)$ therapy in a patient with metastatic thyroid cancer. Internal Medicine 201150 2169-2174. (doi:10.2169/ internalmedicine.50.5740)
37 Jo HJ, Kim YH, Shin DH, Kim MJ, Lee SJ, Jeon DO, Im SG, Jang SK \& Choi JY. Hyponatremia after thyroid hormone withdrawal in a patient with papillary thyroid carcinoma. Endocrinology and Metabolism 2014 29 77-82. (doi:10.3803/EnM.2014.29.1.77)

38 Blevins CH, Killu AM \& Greenlund AC. 52-year-old woman with hypotension, hypothyroidism, and hyponatremia. Mayo Clinic Proceedings 201489 1159-1163. (doi:10.1016/j.mayocp.2013.08.024)

39 Tzoulis P \& Bouloux PM. Inpatient hyponatraemia: adequacy of investigation and prevalence of endocrine causes. Clinical Medicine 201515 20-24. (doi:10.7861/clinmedicine.15-1-20)

40 Liamis G, Milionis HJ \& Elisaf M. Hyponatremia in patients with infectious diseases. Journal of Infection 201163 327-335. (doi:10.1016/j.jinf.2011.07.013)

41 Distiller LA, Polakow ES \& Joffe BI. Type 2 diabetes mellitus and hypothyroidism: the possible influence of metformin therapy. Diabetic Medicine 201431 172-175. (doi:10.1111/dme.12342)

42 Liamis G, Liberopoulos E, Barkas F \& Elisaf M. Diabetes mellitus and electrolyte disorders. World Journal of Clinical Cases 20142 488-496. (doi:10.12998/wjcc.v2.i10.488)

43 Hillier TA, Abbott RD \& Barrett EJ. Hyponatremia: evaluating the correction factor for hyperglycemia. American Journal of Medicine 1999 106 399-403. (doi:10.1016/S0002-9343(99)00055-8)

44 Liamis G, Liberopoulos E, Barkas F \& Elisaf M. Spurious electrolyte disorders: a diagnostic challenge for clinicians. American Journal of Nephrology 201338 50-57. (doi:10.1159/000351804)

45 Verbalis JG, Goldsmith SR, Greenberg A, Korzelius C, Schrier RW, Sterns RH \& Thompson CJ. Diagnosis, evaluation, and treatment of hyponatremia: expert panel recommendations. American Journal of Medicine 2013126 S1-S42. (doi:10.1016/j.amjmed.2013.07.006)

46 Papi G, Corsello SM \& Pontecorvi A. Clinical concepts on thyroid emergencies. Frontiers in Endocrinology 20145 102. (doi:10.3389/ fendo.2014.00102)

47 Liamis G, Filippatos TD \& Elisaf MS. Treatment of hyponatremia: the role of lixivaptan. Expert Review of Clinical Pharmacology 20147 431-441. (doi:10.1586/17512433.2014.911085)

48 Spasovski G, Vanholder R, Allolio B, Annane D, Ball S, Bichet D, Decaux G, Fenske W, Hoorn EJ, Ichai C et al. Clinical practice guideline on diagnosis and treatment of hyponatraemia. Nephrology Dialysis Transplantation 201429 (Supplement 2) i1-i39.

49 Elisaf MS \& Liamis G. Treatment of hyponatremia: what the clinician needs to know. Journal of Nephrology Research 20151 19-21. (doi:10.17554/j.issn.2410-0579.2015.01.2)

50 Filippatos TD, Liamis G \& Elisaf MS. Ten pitfalls in the proper management of patients with hyponatremia. Postgraduate Medicine 2016128 516-522. (doi:10.1080/00325481.2016.1186488)

51 Liamis G, Filippatos TD \& Elisaf MS. Correction of hypovolemia with crystalloid fluids: individualizing infusion therapy. Postgraduate Medicine 2015127 405-412. (doi:10.1080/00325481.2015.1029421)

Received 8 June 2016

Revised version received 6 July 2016

Accepted 1 August 2016 